\title{
Caracterización de la Hoja y Harina de Moringa oleífera
}

\author{
Willam Flores Chana \\ willamflores@hotmail.com \\ Universidad Indígena Boliviana Comunitaria \\ Intercultural Productiva Aymara "Tupak Katari”.
}

\section{RESUMEN}

La moringa oleífera originaria de la India es un árbol perenne caducifolio que crece en cualquier tipo de suelo de las zonas tropicales. El presente trabajo de investigación fija las características propias organolépticas, fisicoquímicas, nutricionales y microbiológicas de la hoja y harina para el uso de la alimentación humana, por ser considerada como una planta medicinal y más nutritiva. Actualmente, en Bolivia están produciendo de forma normal y en menor escala en los departamentos de: Cochabamba, La Paz, Sucre, Tarija y Pando. Se cosecha 4 veces al año, a los 3 meses ya se realiza la primera cosecha de hojas que luego de tratarlas se podrá deshidratar y luego convertir en harina. Las propiedades nutricionales de la hoja y harina incrementan debido a la liberación de agua libre de la estructura celular de la moringa.

Palabras clave: Caracterización organoléptica; fisicoquímica y nutricional de hoja y harina de moringa 


\title{
Moringa oleifera Leaf and Flour characterization
}

\begin{abstract}
The moringa oleifera was born in India, it is a deciduous perennial tree that grows on any type of soil in tropical areas. The research work establishes the organoleptic, physicochemical, nutritional and microbiological characteristics of the leaf and flour. It can use for human food, as it is considered a medicinal and more nutritious plant. Now in Bolivia, they are producing in a normal way and on a smaller scale in the Cochabamba, La Paz, Sucre, Tarija, and Pando cities. It is harvested 4 times a year, at 3 months, the first harvest of leaves is made and after treating them it can be dehydrated and then converted into flour. The nutritional properties of the leaf and flour increase due to the release of free water from the cell structure of moringa.
\end{abstract}

Keywords: organoleptic, physicochemical and nutritional characterization of moringa leaf and flour

Artículo recibido: 05 de Abril 2021 Aceptado para publicación: 28 de Mayo 2021 Correspondencia: willamflores@ hotmail.com Conflictos de Interés: Ninguna que declarar 


\section{INTRODUCCIÓN}

La humanidad desde su civilización ha tenido la necesidad de alimentarse con diferentes alimentos de origen (vegetal y animal), bebidas y agua, para abastecerse. Por ello, han iniciado a producir y almacenar alimentos en condiciones apropiadas (tecnologías creadas), es más, aprendieron a prolongar la vida útil de los alimentos mediante el saber y los conocimientos propios utilizando tecnologías ancestrales como: el deshidratado, el salado, el ahumado, etc. Estos alimentos tratados también han sido almacenados en tecnologías como: Pirwa, sixi y entre otras tecnologías que en la actualidad ya son olvidados sus usos.

En la antigüedad muchas plantas vegetales han sido utilizadas y consumidas como alimentos con fines medicinales, con relaciones astronómicas y protección de malignos, ya que antiguamente no existía medicina convencional al alcance diario, es más, entre muchas hierbas medicinales no generan toxinas que pueden causar daño a nuestro organismo vivo.

Moringa una planta ancestral originaria de India (Enriquez, 2013), que crece en climas tropicales, las hojas tienen cualidades nutricionales sobresalientes, que está entre las más altas de todos los vegetales perenes. Si la planta vegetal tiene nutrientes, esta se puede utilizar para contrarrestar la hambruna o desnutrición del mundo.

En la actualidad, la agroindustria permite dar valor agregado a la hoja de moringa, transformando en infusiones, harina, encapsulado de proteínas, etc., por otro lado, las semillas de moringa son de mucha utilidad como uno de los mejores depurantes y purificadores de aguas de lluvias y aguas turbias. También se emplea en la clarificación de miel y del jugo de la caña de azúcar.

\section{METODOLOGÍA DE INVESTIGACIÓN}

Para lograr los objetivos planteados en la presente investigación, la metodología utilizada fue:

- Visita in situ a las plantaciones de moringa oleífera a la localidad y Municipio de San Ignacio de Velasco del departamento de Santa Cruz.

- Recolección de muestras de hojas de moringa al azar de los arboles identificados.

- Secado o deshidratado de la hoja de moringa en condiciones semi-sombra.

- Elaboración de harina de moringa con molino de rozamiento. 
- Toma de muestras para análisis de laboratorio organolépticas, fisicoquímicas, nutricionales y microbiológicas a la hoja y harina de moringa.

- Trabajo de gabinete, sistematización e interpretación de los resultados.

El presente trabajo de investigación es experimental, ya que se realizan pruebas de ensayos de procesos productivos y análisis fisicoquímicos, nutricional e inocuidad de la hoja y harina de moringa oleífera.

\subsection{Moringa oleífera Lam}

Moringa oleífera Lam. (Castro, 2013) Es un árbol adaptado a trópicos y subtrópicos, nativo del Himalaya en India, pero ampliamente distribuido en otras regiones de India, Asia, África, Sur de florida, Islas del Caribe y América del Sur. Las características del árbol son: altura entre 10-12 m, tronco leñoso y recto de diámetro entre 20-40 cm, rápido crecimiento alcanzando en un año $5 \mathrm{~m}$ de altura, algunas variedades son anuales y pueden alcanzar a vivir 20 años, posee copa abierta tipo paraguas y alta resistencia a plagas y enfermedades.

También (Enriquez, 2013) el cultivo del árbol aporta gran cantidad de nutrientes al suelo, además de protegerlo de factores externos como la erosión y la desecación, puede ser propagado de manera sexual o asexual y cultivado en suelos pobres con escases de lluvia. La moringa pertenece al género de arbusto cuyas hojas, raíces y vainas no maduras se consumen como hortaliza (Guevara, 2012). Todas sus partes (corteza, vainas, hojas, semillas, tubérculos, raíces y flores) son comestibles. El aceite de semilla de moringa es dulce, no se pega, no se seca y no se enrancia; mientras que la torta hecha con semillas se utiliza para purificar el agua. Las semillas también se pueden comer verdes, tostadas, en polvo y en infusión para té.

Según (Castro, 2013), el cultivo de Moringa Oleífera Lam, es de rápido crecimiento y fácilmente cultivable en varias regiones secas del trópico, bajo siembra intensiva puede mantenerse con 500 mil plantas/ha (Velazques, 2015). Requiere un rango de elevación máxima de 1.500 m.s.n.m, precipitación anual entre $250 \mathrm{~mm}$ y $4.000 \mathrm{~mm}$, tolera varios periodos de sequía, aunque se reduce; la producción de hojas, se mantiene a temperatura ente $15-30^{\circ} \mathrm{C}$, aunque puede sobrevivir a $0^{\circ} \mathrm{C}$ por cortos periodos de tiempo con pérdidas de nuevo crecimiento, requiere de suelos con $\mathrm{pH}$ entre 4,5-9, arenosos o con buen drenaje tolerando suelos arcillosos. 


\subsection{Bondades de la moringa oleífera}

De acuerdo a los estudios realizados por (Castro, 2013) y (Garcia, 2013) la moringa se puede aprovechar para uso alimenticio todas las partes de la planta. Las frutas, las hojas, las flores, las raíces y el aceite son altamente apreciados por su valor nutritivo. Ahora en adelante se describe los componentes y sus bondades de cada parte de la planta.

\section{Figura 1: Bondades de la Moringa}

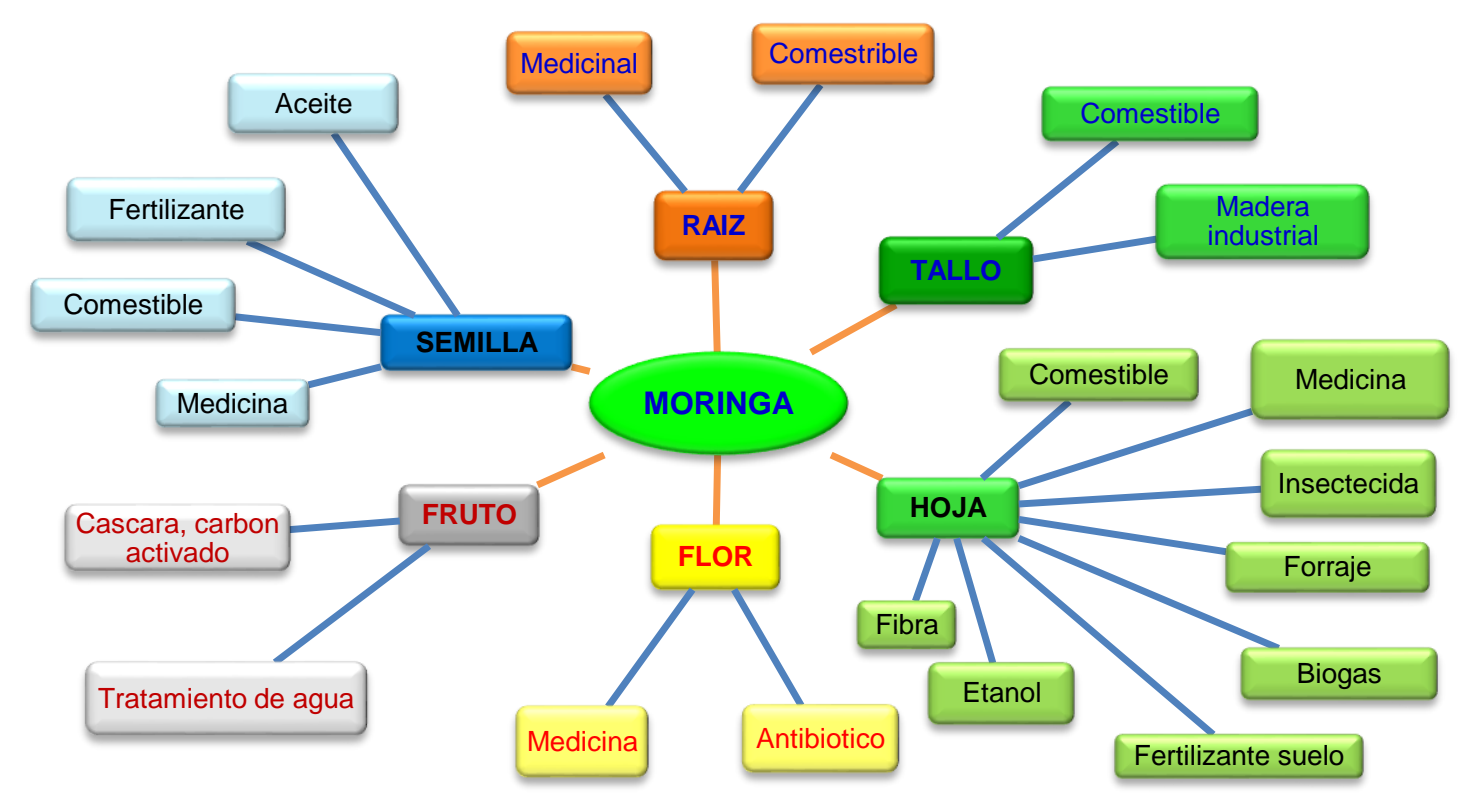

Muchas de las bondades de la moringa han sido demostradas científicamente, su uso como medicinal y nutricional, obviamente algunos aspectos de su composición aún faltan investigar. A continuación, se describen los diferentes usos y sus bondades:

a) Alimentación animal, la moringa se usa como forraje y en la preparación de alimentos balanceados para la alimentación animal, debido que presenta una alta productividad de materia verde en comparación con otros pastos, en su estructura composicional tiene bastante fibra y proteína cruda, mayor contenido de aminoácidos que la soya.

b) Alimentación humana, también todas las partes de la moringa como las frutas, las hojas, las flores, las raíces y el aceite son altamente apreciadas por su valor nutritivo y se utilizan para la elaboración de diferentes platos. Además, se ha demostrado que contienen todos los aminoácidos esenciales para la vida.

c) Uso medicinal, (Garcia, 2013) menciona que las hojas, frutos, raíces y semillas son útiles para combatir la anemia, ansiedad, asma, ataques de parálisis, bronquitis, 
catarro, cólera, congestión del pecho, conjuntivitis, deficiencia de esperma, déficit de leche en madres lactantes, diabetes, diarrea, disfunción eréctil, dolor en las articulaciones, dolores de cabeza, dolor de garganta, escorbuto, esguince, espinillas, falta de deseo sexual femenino, fiebre, gonorrea, hinchazón glandular, hipertensión arterial, histeria, impurezas en la sangre, infecciones cutáneas, llagas, malaria, otitis, parasitismo intestinal, picaduras venenosas, problemas de la vejiga y la próstata, soriasis, trastornos respiratorios, tos, tuberculosis, tumores abdominales, úlceras, etc.

d) Actividad antimicrobiana, Estudios bacteriológicos demostraron la actividad antimicrobiana de los extractos de semillas de moringa, los cuales floculan bacterias Gram positivas y Gram negativas del mismo modo que lo hacen con los coloides del agua. En una investigación muy reciente realizada en Kenya se demostró la actividad antimicrobiana de extractos de semillas de M. oleifera sobre las bacterias Salmonella typhii, Vibrio cholerae y Escherichia coli, causantes de la fiebre tifoidea, el cólera y la gastroenteritis.

e) Actividad antioxidante, Estudios in vitro demostraron que los extractos de hojas, frutos y semillas de moringa, debido a sus propiedades antioxidantes, protegen las células vivas del daño oxidativo del ADN asociado con el envejecimiento, el cáncer y las enfermedades degenerativas.

f) Actividad Antiinflamatoria, Debido a su alto contenido de fenoles, vitaminas, ácidos grasos omega 3, aminoácidos, glutatión, esteroles e isocianatos, los extractos de las raíces y de las semillas de M. oleifera contribuyen directa o indirectamente a la protección contra enfermedades inflamatorias (Ezeamuzle, Ambadederomo, Shode y Ekwebelem, 1996).

g) Purificación de agua potable, El uso de M. oleifera en el tratamiento de aguas con el fin de purificarlas es una práctica antigua. En algunas fuentes de literatura popular se dice que este uso está recogido en el siguiente pasaje del Antiguo Testamento: "...no pudieron beber las aguas de Mara, porque eran amargas (...) Moisés clamó a Jehová, y Jehová le mostró un árbol; y lo echó en las aguas, y las aguas se endulzaron (Éxodo 15:22-27). Independientemente de los atributos de la moringa y del valor teológico del mencionado pasaje bíblico, los argumentos para relacionarlos carecen de fundamento científico. 


\subsection{Proceso de elaboración de deshidratado y harina de moringa}

$\checkmark$ Deshidratado de moringa. - Deshidratar significa eliminar, quitar el agua libre del cualquier alimento fresco (hoja de moringa) en condiciones de semi-sombra o sometidos a tratamientos térmicos controlados de tiempo y temperatura del ambiente en la que es sometida.

$\checkmark$ Cosecha. - Es una acción empleada para recolectar la hoja de las ramales, tallo del árbol de moringa, cuando ya esté madurada o que las hojas tienen su aroma característico propio. También es importante considerar en el momento de la cosecha el manipuleo, transporte, y la opilación entre hojas, para que no se forzara el aplastamiento y compresión del agua de la hoja de moringa.

$\checkmark$ Lavado. - Una vez cosechada las hojas de moringa, se debe proceder a realizar el lavado o limpieza por el método de inmersión en agua potable. Esta con el objetivo de eliminar las contaminaciones físicas adheridas como: la paja, heces fecales de los pájaros y de los insectos, polvo, etc., con este tratamiento se garantiza su posterior operación que es el secado.

$\checkmark$ Secado. - Cuando la hoja de moringa pasa por el lavado, después de escurrir el agua, se debe llevar al secado bajo sombra, para que los rayos solares no afecten a sus componentes nutricionales. El secado realizado bajo sombra mantiene su color original y la harina tiene mejor aspecto.

$\checkmark$ Molido. - Es fundamental utilizar equipos adecuados que puedan reducir el tamaño de la hoja de moringa, con fin de mantener sus propiedades nutricionales, es más, esta operación permite tener más vida útil del producto terminado, por tener reducido contenido de humedad y por tener tamaños muy reducidos.

$\checkmark$ Envasado. - Una vez secado la hoja de moringa, de inmediato se deben envasar herméticamente en envases recomendados a fin de no perder el aroma característico.

\section{Foto 2: Hoja deshidratada y harina de moringa}

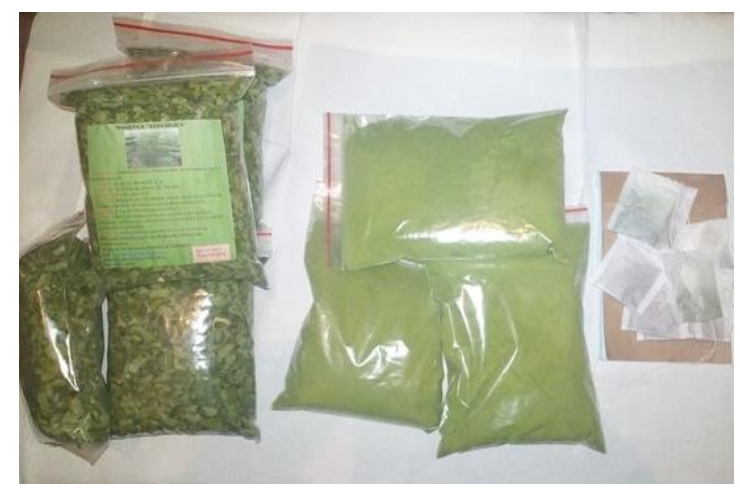




\subsection{Diseño experimental y análisis estadístico}

Cuadro 1: Diseño y modelo experimental

\begin{tabular}{|c|c|}
\hline Factor & Harina de moringa \\
\hline Variables de estudio & Organoléptica, fisicoquímica, y nutricional \\
\hline Variables de respuesta & $\begin{array}{l}\text { Caracterización organoléptica, fisicoquímica, } \\
\text { nutricional y microbiológica de la hoja y harina de } \\
\text { moringa. }\end{array}$ \\
\hline
\end{tabular}

Para conocer las cualidades propias de la hoja y harina de moringa, se ha planteado un modelo de diseño experimental cuasi-experimental de un solo factor, únicamente para describir la deferencia de sus componentes morfológicas externas y sus propiedades fisicoquímicas del producto.

\subsection{Resultados de laboratorio}

Cuadro 2: Características y propiedades propias de la hoja y harina de moringa

\begin{tabular}{|c|c|c|c|}
\hline \multicolumn{4}{|c|}{ oleifera } \\
\hline ASPECTOS & PARÁMETRO & HOJA & HARINA \\
\hline & PAKAIVITU & Valor g/100g & Valor g/100g \\
\hline \multirow{4}{*}{ Organoléptico } & Color & Verde & Verde \\
\hline & Olor & Característico & Característico \\
\hline & Sabor & Característico & Característico \\
\hline & Aspecto & Característico & Característico \\
\hline \multirow{6}{*}{ Fisicoquímica } & Valor energético & 358,00 & 358,00 \\
\hline & Humedad & 9,27 & 8,00 \\
\hline & Proteína & 23,19 & 26,41 \\
\hline & Grasa & 8,89 & 6,89 \\
\hline & Carbohidratos & 47,05 & 47,65 \\
\hline & Cenizas & 11,60 & 11,05 \\
\hline \multirow{5}{*}{ Nutricional } & Calcio & 2618,00 & 2679,12 \\
\hline & Fosforo & 242,71 & 315,76 \\
\hline & Hierro & 60,48 & 17,62 \\
\hline & Vit A & 9255,24 & 6314,47 \\
\hline & Vit C & 149,38 & 144,23 \\
\hline \multirow{3}{*}{ Microbiológico } & Staphylococcus aureu & $<1,0 \times 10^{1} \mathrm{UFC} / \mathrm{g}$ & $<1,0 \times 10^{1} \mathrm{UFC} / \mathrm{g}$ \\
\hline & Escherichia coli & $<1,0 \times 10^{1} \mathrm{UFC} / \mathrm{g}$ & $<1,0 \times 10^{1} \mathrm{UFC} / \mathrm{g}$ \\
\hline & Salmonella & Ausencia 50g & Ausencia 25g \\
\hline
\end{tabular}

Fuente.- INLASA, 2017 
Los resultados que se muestran en el cuadro anterior son promedios de la hoja y harina de moringa, las mismas son resultados de un análisis del modelo experimental propuesto para la investigación. Los análisis técnicos y estadísticos son descritos a continuación:

\section{ANÁLISIS ESTADÍSTICO}

Para conocer las características propias de la moringa, en este acápite empezaremos a recordar la hipótesis planteada inicialmente que decía como $\mathrm{H}_{\mathrm{o}}$ las propiedades organolépticas, fisicoquímica y nutricionales son iguales a la de hoja frente a la harina de moringa y como $\mathrm{H}_{\mathrm{a}}$ al menos unos de las propiedades organoléptica, fisicoquímica y nutricionales son diferente a la de hoja frente a la harina de moringa. A continuación, se tiene el resultado del laboratorio y de estadística del diseño experimental al azar con un solo factor y al $95 \%$ de confiabilidad.

Las características organolépticas de la hoja de moringa no se han alterado con respecto a la harina de moringa, en este caso se acepta la hipótesis nula debido que el p-valor es mayor al 0.05 del error, asimismo, comparando con Tukey se demuestra que la hoja y harina de moringa tiene un color verde, Olor, sabor y aspecto característico, el cual se podrá observa en el cuadro 2 y figura 2 respectivamente.

Las características Fisicoquímicas de la hoja y la harina de moringa son las siguientes:

- El valor energético encontrado en el laboratorio de la hoja y harina de moringa son las mismas, es decir, no se ha alterado con la operación molienda al rozamiento, entonces se acepta la hipótesis nula.

- Por otro lado, la humedad de la hoja de moringa en laboratorio es de $9.27 \%$, en la harina de moringa bajo al $8 \%$, esto debido a que las partículas de hoja y harina de moringa es totalmente diferente. Este es un indicador que ha reducido la actividad de agua en harina, lo que conlleva a no proliferarse los microorganismos patógenos principalmente.

- En cuanto al contenido de proteína se demuestra en el laboratorio que en la hoja de moringa es $23.19 \%$ en cambio en la harina de moringa ha incrementado al $26.41 \%$. Estadísticamente se tiene el resultado de ANOVA que el p-valor 0.9522 es mayor a 0,05, con este resultado se acepta la hipótesis nula, lo que quiere decir, que no existe diferencia significativa en cuanto al contenido de proteína, por otro lado se ha verificado con tukey, que evidentemente que las medias de hoja es 26.22 y de la harina es 26.44, que no existe una diferencia significativa. 
- De acuerdo al resultado de laboratorio, en cuanto al contenido de la grasa en hoja de moringa es $8,89 \%$ y en harina de moringa es $6,89 \%$. Se puede notar que ha reducido el contenido de la grasa de hoja frente a la harina con la operación de rozamiento, ahora, con ANOVA se tiene que el p-valor 0,0611 es mayor a 0,05, esto significa que se acepta la hipótesis nula, concretando que no existe diferencia significativa, en cuanto al contenido de grasa en la hoja frente a la harina; la misma se ha validado con tukey, que la media de hoja es 8,84 en cambio de harina es 6,21 respectivamente.

- En cuanto al contenido de carbohidratos en laboratorio en hoja de moringa es 47,05 $\%$ y en la harina es de 47,65 \%, y el resultado de ANOVA indica que el p-valor 0,9676 es mayor a 0,05 . Con este resultado se acepta la hipótesis nula, confirmando que no existe una diferencia significativa en el contenido de carbohidratos de la hoja frente a la harina de moringa. Ahora, dicha confirmación se ha validado con tukey que la media de hoja es de 46,97 en cambio de la harina es de 47,00 respectivamente, estos valores confirman que no se ha alterado los carbohidratos en hoja ni en harina con la operación de rozamiento.

- Finalmente, el resultado del laboratorio demuestra que la hoja de moringa tiene 11,60 $\%$ de ceniza, en cambio la harina de moringa tiene 11,05\% de ceniza. Esto significa que la concentración de ceniza en ambas son las mismas, es decir, no existe una diferencia significativa.

Las características nutricionales que presentan la hoja y la harina de moringa, se describen a continuación:

- El resultado de laboratorio en cuanto el contenido de calcio en moringa, indica que en hoja es 2618,00 mg y en harina 2679,12 mg. Es así, que ANOVA indica que el pvalor 0,0601 es mayor a 0,05, con este resultado se acepta la hipótesis nula, lo que significa que no existe diferencia significativa en la concentración de calcio en la hoja, ni en la harina de moringa, esta se ha validado con Tukey lo que indica que la media de hoja es de 2621,66 y en la harina es de 2667,84 respectivamente.

- En cuanto al resultado de laboratorio el contenido de fosforo en moringa, indica que en la hoja es $242.71 \mathrm{mg}$ y en harina es 315,76 mg. Es así que ANOVA indica que el p-valor 0,00441 es menor a 0,05 , con este resultado se rechaza la hipótesis nula y se acepta la alterna, lo que significa que si existe diferencia significativa en la concentración de fosforo en la hoja frente a la harina de moringa, esta se ha validado 
con Tukey lo que indica que la media de hoja es de 246,52 y en la harina es de 318,66 respectivamente, es notorio que en la harina ha incrementado debido a la reducción de humedad.

\section{Test:Tukey Alfa=0,05 DMS=20,56681}

Error: $22,8880 \mathrm{gl}: 2$

Moringa Medias n E.E.

Hoja 246,52 23,38 A

Harina $318,6623,38 \quad$ B

Medias con una letra común no son significativamente diferentes ( $p>0,05$

- En cuanto al resultado de laboratorio, el contenido de hierro en moringa indica que en la hoja es 60,48 mg y en harina es 17,62 mg. ANOVA indica que el p-valor 0,0004 es menor a 0,05 , con este resultado se rechaza la hipótesis nula y se acepta la alterna, lo que significa que si existe diferencia significativa en la concentración de hierro en la hoja frente a la harina de moringa, esta se ha validado con Tukey lo que indica que la media de hoja es de 59,86 y en la harina es de 18,15 respectivamente, es notorio que en la harina bajo por la operación de rozamiento.

\section{Test:Tukey Alfa=0,05 DMS=3,50648}

Error: 0,6653 gl: 2

Moringa Medias n E.E.

Harina $18,1520,58 \mathrm{~A}$

Hoja $\quad 59,86 \quad 20,58 \quad$ B

Medias con una letra común no son significativamente diferentes ( $p>0,05)$

- En cuanto al resultado de laboratorio el contenido de Vitamina " $A$ " en moringa, indica que en la hoja es 9255,24 $\mu \mathrm{g}$ y en harina es $6314,47 \mu \mathrm{g}$, por lo cual, ANOVA indica que el p-valor 0,0054 es menor a 0,05, con este resultado se rechaza la hipótesis nula y se acepta la alterna, lo que significa que, si existe diferencia significativa en la concentración de vitamina "A", en la hoja frente a la harina de moringa. Esta se ha validado con Tukey, lo que indica que la media de hoja es de 9112,07 y en la harina es de 6149,92 respectivamente, es notorio que en la harina ha bajado por la operación de rozamiento, por otro lado, se sabe que la Vitamina "A" es foto y termolábil.

Test:Tukey Alfa=0,05 DMS=937,69838

Error: $47577,4287 \mathrm{gl}: 2$ 


\section{Moringa Medias n E.E.}

Harina 6149,92 $2154,24 \mathrm{~A}$

\section{Hoja $9112,07 \quad 2154,24 \quad$ B}

Medias con una letra común no son significativamente diferentes ( $p>0,05)$

- Por último, dentro del estudio nutricional el resultado de laboratorio en cuanto al contenido de Vitamina “C” en moringa, indica que en hoja es 149,38 $\mu \mathrm{g}$ y en harina es 144,23 $\mu \mathrm{g}$, ahora, ANOVA indica que el p-valor 0,1024 es mayor a 0,05, con este resultado se acepta la hipótesis nula, lo que significa que no existe diferencia significativa en la concentración de Vitamina " $C$ " en la hoja ni en la harina de moringa, esto se ha validado con Tukey lo que indica que la media de hoja es de 150,87 y en la harina es de 145,41 respectivamente.

Finalmente, la inocuidad o la carga Microbiológica que se ha encontrado en el laboratorio, están dentro de la norma alimentaria. Se han analizado Staphylococcus aureu, Escherichia coli y salmonella. Por lo que podemos decir que los productos hoja y harina de moringa son aptos para el consumo humano sin ninguna novedad.

\section{Figura 2: Resultados estadísticos de hoja y harina de moringa}

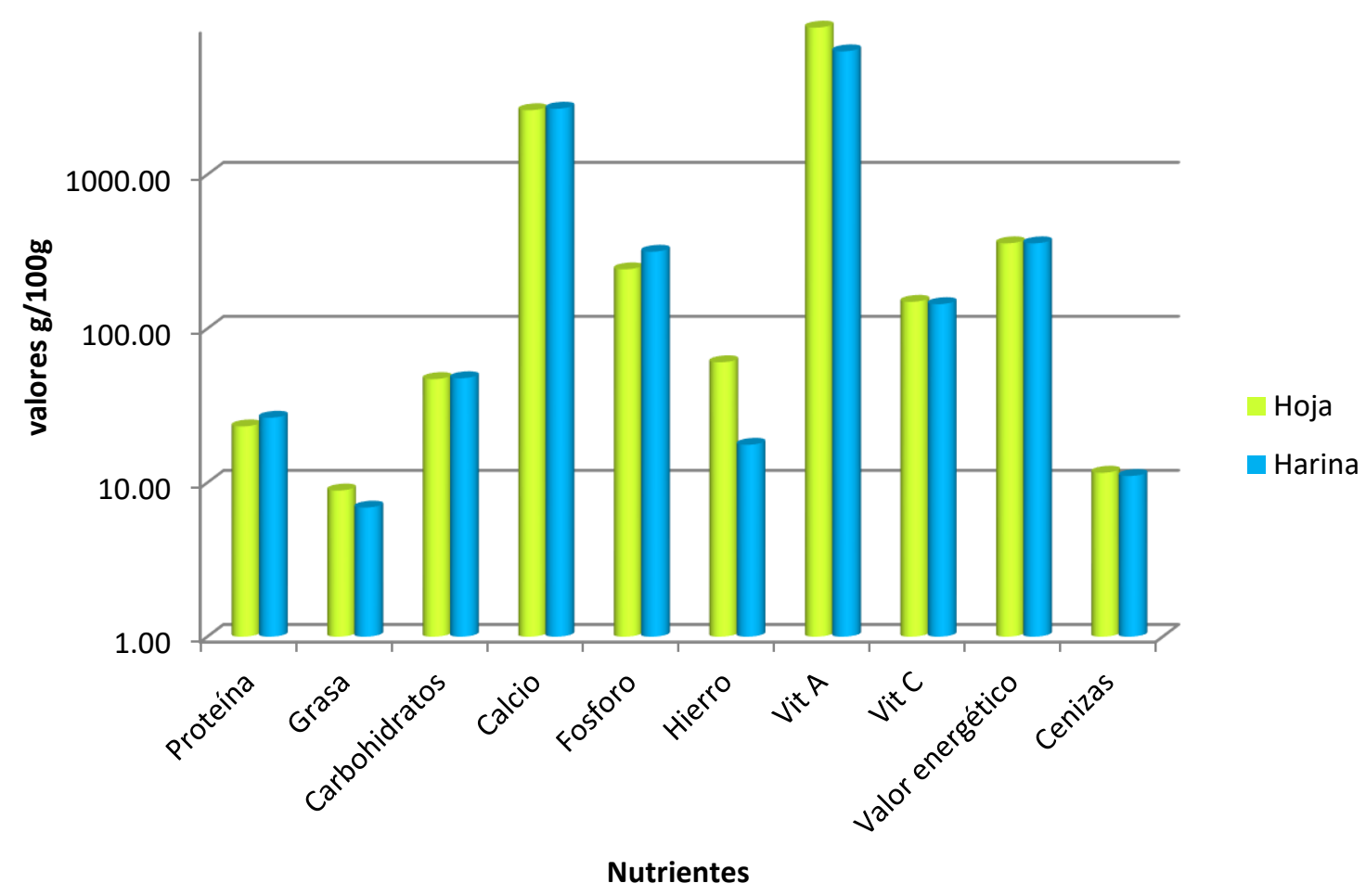




\section{CONCLUSIONES Y RECOMENDACIONES}

El presente trabajo de investigación realizada acerca de la hoja y harina de moringa procedentes de la localidad y Municipio de San Ignacio de Velasco tienen los siguientes resultados:

- En cuanto a las características organolépticas, se demuestra que la hoja y harina de moringa tienen color verde, Olor, sabor y aspecto; que es propia y característico. O sea, no se ha alterado casi nada.

- En cuanto a las características fisicoquímicas (Valor energético, humedad, proteína, grasa, carbohidratos y ceniza) de la hoja y harina de moringa, no ha sufrido ningún cambio brusco en cuanto a la composición fisicoquímica, ni ha afectado la operación de rozamiento.

- En cuanto a las características nutricionales (Calcio, fosforo, Hiero, Vitamina "A" y Vitamina "C") de la hoja y harina de moringa en calcio y vitamina "C" no hubo cambios bruscos. En cambio, en cuanto a fosforo, hierro y Vitamina "A" si existió cambios.

- Finalmente, en cuanto a la inocuidad, la hoja y harina de moringa se puede emplear para la alimentación humana sin ningún riesgo. Los resultados de laboratorio están dentro de la norma, esto quiere decir que se han empleado las buenas prácticas de manufactura de forma adecuada y cuidadosa.

\section{RECOMENDACIONES}

- Estudiar los taninos de la moringa.

- Estudiar y validar lo que se emplea como medicina humana.

- Estudiar y validar el uso de la moringa en la dieta de los animales.

\section{BIBLIOGRAFÍA}

Andrea, A. (2014). Elaboracion de bebida refrescante y nutritiva a base de stevia y moringa como una alternativa para la agroindustria de El Salvador. El Salvador.

Arias, C. (2014). Estudio de las posibles zonas de introduccion de la moringa oleifera lam ene la peninsula iberica islas baleares e islas canarias. España.

Castro, A. (2013). el arbol de moringa una alternativa renovable para el desarrollo de los sectores economicas y ambientales de Colombia. Colombia. 
Contreras, S. (2009). Estudio de factibilidad tecnico economico para la agroindustrializacion de los productos derivados del arbol de teberinto moringa en el Salvador. El Salvador.

Deltoro, J. (2011). valoracion de la propiedades nutricionales de moringa en el departamento de Bolivar. Cartagena.

Enriquez, R. (2013). Productos agroindustriales con alto valor nutricional en la amazonia boliviana. Pando Bolivia.

FH. (2015). moringa un aliado en la lucha contra desnutricion. Niger.

Garcia, M. (2013). Potenciales aplicaciones de Moringa oleifera. una revisión crítica. Matanza, Cuba.

Gomez, K. (2013). Evaluacion de rendimiento de extraccion y caracterizacion fitoquimica de la fraccion extraible de semilla de moringa a nivel laboratorio. Guatemala.

Gonzales, E. (2012). Caracterizacion fisico-quimica y sensorial del aceite de semilla de moringa oleifera La,. Habana Cuba.

Guevara, J. (2012). caracterizacion de extractos de moringa oleifera y evaluacion de sus condiciones de infusion ene sus caracteristiucas fisicoquimicas . Zamorano, Honduras.

Gutierez, D. (2015). evaluacion de la composicion quimica y degradabilidad ruminal en situ de ensilaje mixto con pennisetum purpureum cv. Cuba CT-169 Moringa Oleifera. Habana Cuba.

INE. (2013). Censo Agropecuario 2013 Bolivia. La Paz Bolivia.

Mera, C. (2016). efecto de la moringa eleifera en el tratamiento de aguas residuales en la cauca colombia. Colombia.

Olson, M. (2011). Moringa oleifera un arbol multiuso para las zonas tropicales secas. Mexico.

Ramirez, G. (2012). caracterizacion quimica de moringa oleifera utilizando espectrometria de absorcion atomica. España.

Ramos, M. (2012). Revista ciencia, tecnologia e innovacion. Chuquisaca Bolivia.

Uquillas, N. (2017). Moringa y su uso culinario. Quito ecuador. 
Vargas, V. (2012). Elaboracion de te aromatico a base de plantas cedron y toronjil procesado con stevia endulzante natural, utilizando el metodo de deshidratacion. Ecuador.

Velazques, M. (2015). Moringa (moringa leifer) usos ponciales en la agricultura, industria y medcina. Mexico.

Vergara, J. (2015). Riesgos de utilizar la moringa oleifra para el tratamiento de enfermedades sin los estudios y evidencias cientificas que avalen su eficiacia y seguridad en tales enfermedades. Panama. 